Check for updates

1 University Hospitals of Coventry and Warwickshire, Coventry, UK

2 South Asian Health Foundation, Coventry, UK

Correspondence to: K Patel

Cite this as: BMJ 2021;375:n2456 http://dx.doi.org/10.1136/bmj.n2456

Published: 11 October 2021

\title{
Ensuring an equitable recovery for the NHS
}

\author{
Health leaders must seize this historic opportunity to level up \\ Kiran Patel, ${ }^{1}$ Rachel Chapman, ${ }^{1}$ Raj Gill, ${ }^{2}$ Justine Richards ${ }^{1}$
}

The effect of the pandemic on non-covid related healthcare is only now starting to be felt by patients and healthcare systems. At least 4.5 million people are estimated to be waiting for elective care in the $\mathrm{UK},{ }^{1}$ and the backlog may rise to 13 million ${ }^{2}$ and take over a decade to clear. The backlog arose after a sharp fall in patient demand at the height of the first wave of the pandemic in the spring and summer of 2020 (driven by the instruction to stay at home to protect the NHS and a fear of coming to hospital) coupled with reduced capacity as resources were rightly allocated to meet the needs of people with covid-19.

During March to December 2020, there were 2.9 million fewer elective admissions to the NHS than in the corresponding period in 2019. ${ }^{3}$ Consequently, we now have an emerging demand on elective care that the NHS cannot meet using conventional means. ${ }^{4}$ The NHS currently runs at close to $100 \%$ operational efficiency, and there is clearly insufficient slack in the system to cope with surges in demand.

Today, as the NHS attempts to recover and restore business as usual, emergency care continues to see many patients with covid-19 despite a successful vaccination programme; the NHS workforce is fatigued or absent because of isolation measures, making operational planning a challenge; and other patients wait to be seen and treated. What are our options to recover fairly? 5

Clinical prioritisation ${ }^{7}$ must continue to drive delivery, but prioritisation should change when the clinical status of a patient changes rather than focusing solely on the number of weeks a patient has waited. This will need patients to be actively managed while on waiting lists so that care can be expedited, or indeed delayed, if needs change. Coupling provision to clinical and socioeconomic outcomes is essential. ${ }^{8}$

In addition, every healthcare interaction should be used to promote health preservation and wellbeing, using these opportunities to identify and manage problems such as cardiovascular risk factors and early cancer symptoms, late recognition of which drives health inequality. Optimising the diagnosis and management of comorbidities while people are on waiting lists will help improve outcomes and reduce inequality. The NHS should urgently evaluate and deliver initiatives such as screening for cardiovascular risk factors, dementia, atrial fibrillation, and domestic abuse during attendance for covid-19 vaccination or outpatient appointments.

We should also seek out patients with unmet clinical need. Population health management should be used to target populations and communities in which we know people present with disease at a later stage than in more affluent areas. ${ }^{8} \mathrm{NHS}$ waiting lists must swell with more needful patients, even at a time of substantial backlog, if we are to reduce inequalities. We must not accept a system that increases waiting lists in deprived areas but increases activity in affluent areas. ${ }^{9}$

Social determinants and social value judgments ${ }^{10}$ must become integral to decision making for individual patients. It's time to consider whether potential gains in ability to work, study, and care should feature alongside gains in quality adjusted life years when determining prioritisation for treatment.

Finally, rapidly transforming healthcare could improve outcomes, performance, and value. The pandemic forced the NHS to use artificial intelligence, virtual and remote appointments, one stop services, workforce innovation, and private sector partnerships, and to make more efficient use of its estate. ${ }^{6}$ Robust evaluation of these taxpayer funded initiatives should inform decisions about priorities, guiding expenditure of the additional $€ 5.4 \mathrm{bn}(€ 6.4 \mathrm{bn}$; $\$ 7.3 \mathrm{bn}$ ) allocated by the Treasury to support recovery of the NHS and social care.

The non-covid related effects of the pandemic on patients and healthcare systems will become clearer over the coming months and years. If health inequity were a disease (and in some ways it is) we would surely seek to prevent or treat it. We must do both now, to stop inequality widening further as the country and the NHS recover from the pandemic. The journey has already started and needs clinical and political leadership, commitment, and evidence informed or analytically driven policy to protect the most vulnerable communities and individuals.

Competing interests: We have read and understood BMJ policy on declaration of interests and have no interests to declare.

Provenance and peer review: Commissioned; not externally peer reviewed.

NHS waiting list in England hits record 5.45 million. BBC News 2021 Aug 12. https://www.bbc.co.uk/news/health-58186708

2 Stoye G, Walker M, Zaranko B. Could NHS waiting lists really reach 13 million? 2021 https://ifs.org.uk/publications/15557.

3 Burn S, Propper C, Stoye G, Warner M, Apylin P, Bottle A. What happened to English NHS hospital activity during the covid-19 pandemic? Institute for Fiscal Studies, 2021.

4 Gardner T, Fraser C. Longer waits, missing patients and catching up: how is elective care in England coping with the continuing impact of COVID-19? Health Foundation, 2021. https://www.health.org.uk/news-and-comment/charts-and-infographics/how-is-elective-care-coping-with-the-continuing-impact-of-covid-19

Siciliani L. Waiting times: evidence of social inequalities in access for care. In: Sobolev B, Levy A, Goring S, eds. Springer, 2015, doi: 10.1007/978-1-4899-7673-4_17-1.

$6 \quad$ NHS England. NHS’s $£ 160$ million 'accelerator sites' to tackle waiting lists. 2021. https://www.england.nhs.uk/2021/05/nhss-160-million-acceleratorsites-to-tackle-waiting-lists/ 
$7 \quad$ NHS. Clinical prioritisation of waiting lists for endoscopy and diagnostic procedures. 2021. www.england.nhs.uk/coronavirus/wp-content/uploads/sites/52/2021/05/C1328-clinical-prioritisation-of-waiting-lists-for-endoscopy-and-diagnostic-procedures-guidance_June2021_v2.pdf

8 Pell JP, Pell AC, Norrie J, Ford I, Cobbe SM. Effect of socioeconomic deprivation on waiting time for cardiac surgery: retrospective cohort study. BMJ 2000;320:15-8.

doi: 10.1136/bmj.320.7226.15 pmid: 10617517

9 Mahase E. Most deprived areas in England have fastest growing waiting lists, says think tank. BMJ2021;374:n2373. doi: 10.1136/bmi.n2373 pmid: 34580117

10 Biron L, Rumbold B, Faden R. Social value judgments in healthcare: a philosophical critique. J Health Organ Manag 2012;26:317-30. doi: 10.1108/14777261211238963. pmid: 22852454 